\title{
O Brasil no Órgão de Solução de Controvérsias da OMC: soft balancing?
}

\section{Brazil in the WTO Dispute Settlement Body: soft balancing?}

DOI: $10.21530 /$ ci.v13n3.2018.762

\author{
Daniel castelan ${ }^{1}$ \\ Leandro Wolpert dos Santos ${ }^{2}$
}

\section{Resumo}

O objetivo do artigo é analisar se a atuação do Brasil no Órgão de Solução de Controvérsias da OMC (OSC) reflete uma estratégia de soft balancing por parte do governo brasileiro. Para atingir o propósito, foram realizadas as seguintes tarefas: (i) identificação de se e quando o balanceamento do poder estadunidense se tornou um propósito da política externa brasileira, através da análise de discursos e documentos oficiais; (ii) análise dos números de casos levados pelo governo brasileiro no período, em comparação com países aliados dos Estados Unidos, para verificar se há algum viés no uso do OSC que indique o uso político desse mecanismo; e (iii) análise do contencioso aberto contra os EUA sobre subsídios ao algodão, em 2003. Os resultados indicam que, embora o conceito seja adequado para interpretar algumas iniciativas de política externa, há limitações em sua aplicação à atuação do governo brasileiro no OSC, pois as competências para a abertura de casos não eram exclusivas do Itamaraty e também porque o número de casos abertos contra os EUA reduziu-se bastante no momento em que, discursivamente, as críticas à concentração do poder mundial se tornavam mais recorrentes. Sendo assim, recorrer a tal interpretação desvia o analista de buscar explicações em outros níveis de análise que podem ter sido determinantes no caso em questão.

Palavras-chave: Soft Balancing; Política Externa Brasileira; Estados Unidos; Órgão de Solução de Controvérsias; Organização Mundial de Comércio.

1 Doutor em Ciência Política pelo Instituto de Estudos Sociais da Universidade do Estado do Rio de Janeiro (IESP/UERJ), é professor de Relações Internacionais da Universidade Federal de Santa Catarina (UFSC), onde integra o Grupo de Análise de Política Externa (GAPE).

2 Doutorando em Ciência Política no Instituto de Estudos Sociais e Políticos da Universidade do Estado do Rio de Janeiro (IESP/UERJ), é bolsista CNPq e integrante dos grupos de pesquisa GAPE (Grupo de Análise de Política Eterna), OPSA (Observatório Político Sul-Americano) e NEAAPE (Núcleo de Estudos Atores e Agendas de Política Externa).

Artigo submetido em 17/12/2018 e aprovado em 02/10/2018. 


\begin{abstract}
The objective of this paper is to analyze whether Brazil's role in the WTO Dispute Settlement Body (DSB) reflects a strategy of soft balancing by the Brazilian government. To accomplish this purpose, the following tasks were carried out: (i) identification of if and when the balance of US power became a purpose of Brazilian foreign policy, through the analysis of speeches and official documents; (ii) analysis of the numbers of cases taken by the Brazilian government in the period, compared to allied countries of the United States, to verify if there is any bias in the use of the DSB that indicates the political use of this mechanism; and (iii) analysis of the litigation opened against US cotton subsidies in 2003. The results indicate that although the concept is adequate to interpret some foreign policy initiatives, there are limitations in its application to the Brazilian government's role in the DSB, because the powers to open cases were not unique to the Itamaraty, and also because the number of cases opened against the US was greatly reduced at a time when, discursively, criticisms of the concentration of world power became more recurrent. Thus, recourse to such an interpretation diverts the analyst from seeking explanations at other levels of analysis that may have been decisive in the case in question.
\end{abstract}

Keywords: Soft balancing; Brazilian Foreign Policy; United States; Dispute Settlement Body; World Trade Organization.

\title{
Introdução
}

Em novembro 2009, a revista The Economist estampou em sua capa uma foto do Cristo Redentor decolando, abaixo de um título não menos enfático:"Brazil takes off". A imagem bem expressava a expectativa, comum à época, de que o Brasil crescia e, em decorrência, teria mais espaço na discussão dos grandes temas da política internacional. O reconhecimento não era inédito. Termos como "emergentes", "potências médias", "global players" e "grandes mercados emergentes" visitaram as análises sobre política externa com a mesma frequência com que ciclos econômicos de tempos em tempos renovam suas expectativas de desenvolvimento. Se, no final dos anos de 1970, estiveram em pauta os Newly Industrialized Countries (NICs), na primeira década dos anos 2000 os holofotes se dirigiram para os BRICS.

Nesse período, o debate foi acompanhado por análises sobre as estratégias de política externa perseguidas por tais países com o fim de expandir seu papel na política internacional, tanto no relacionamento com a região, como com grandes potências ou instituições internacionais (HURREL, 2009; DESTRADI, 2010; 
SCHWELLER; PU, 2011; STEPHEN, 2012; FLEMES, 2013). Parte dessa literatura, de tradição realista, defendeu a tese de que o Brasil, assim como outros emergentes, teria adotado uma estratégia de soft balancing (balanceamento brando), com vistas a conter o poder e a influência das potências estabelecidas, em especial os Estados Unidos, no processo decisório global, por meio de iniciativas diplomáticas e institucionais predominantemente não militares, tais como: entendimentos informais e exercícios cooperativos ad hoc; colaboração através de arranjos diplomáticos em instituições regionais ou internacionais; reforço da coesão econômica entre os alinhados, através, por exemplo, da construção de blocos econômicos regionais, sem a participação dos Estados Unidos; transmissão de sinais diplomáticos do comprometimento de resistir às ambições do Estado dominante; entre outros (HURREL, 2009; FLEMES, 2009, 2010; FONSECA JR., 2012; LOPES, 2017).

O ativismo brasileiro no Órgão de Solução de Controvérsias (OSC) da Organização Mundial de Comercio (OMC) foi utilizado, pela literatura, como uma das evidências da estratégia de balanceamento brando na política externa brasileira (HURREL, 2009; FLEMES, 2009, 2010). Segundo Hurrel (2009), as ações movidas pelo Brasil contra os EUA no OSC, além de atenderem a interesses comerciais concretos, teriam visado ao mesmo fim de outras práticas de soft balancing, qual seja, desconcentrar o poder mundial. Isso porque instituições internacionais como a OMC permitem que países de menor poder relativo contra-arrastem, ainda que com limitações, a proeminência das potências dominantes, em particular os Estados Unidos. Assim, através das instituições internacionais, países como Brasil e a Índia seriam capazes de

acorrentar Gúliver [em referência aos EUA] de todas as formas possíveis, independentemente de quão finas as amarras individuais possam ser. Não é surpreendente, portanto, que o Brasil e a Índia sejam o quarto e o quinto países que mais ativamente reclamem no mecanismo de solução de controvérsias da Organização Mundial de Comércio (OMC). (HURREL, 2009, p. 27)

Entretanto, ao defender o argumento de que a política brasileira na OSC atende à estratégia de soft balancing, Hurrel (2009) não examinou um pressuposto necessário para sua validade: qual seria a motivação, intenção ou propósito do governo brasileiro ao abrir os contenciosos na OMC. E, sem avaliá-las, é impossível qualificar as ações no OSC como estrategicamente voltadas ao soft balancing. Flemes (2009; 2010) cometeu o mesmo equívoco ao replicar o argumento de 
Hurrel (2009) e não fornecer evidências de que os governantes brasileiros foram motivados por razões de política de poder ao decidirem acionar os Estados Unidos no OSC. Desse modo, ambos os autores deixaram de levar em conta explicações alternativas para o ativismo brasileiro no OSC.

O objetivo deste trabalho consiste, pois, em analisar mais criteriosamente se as ações brasileiras no OSC podem ser qualificadas como soft balancing, como forma de refletir sobre os rendimentos analíticos desse conceito. Realizamos as seguintes tarefas com esse fito: depois de apresentar a tese do soft balancing na seção 1, na seção 2, buscamos evidências gerais de que tal propósito esteve presente nas diretrizes gerais da política externa brasileira recente, recorrendo a discursos e documentos oficiais. Em seguida, na seção 3, através do levantamento de alguns números sobre a atuação do Brasil no OSC e de um estudo de caso típico, buscamos avaliar o argumento de que o Brasil utilizou tal órgão como uma estratégia de soft balancing, nos termos definidos pela literatura sobre o assunto.

\section{A tese do soft balancing}

Com o incremento do unilateralismo na política externa dos Estados Unidos a partir da "Doutrina Bush" de guerra ao terror e a reação assertiva de países como Alemanha, França e Rússia contra os planos estadunidenses de invasão militar do Iraque no início dos anos 2000, parte da literatura ocidental, influenciada pelos aportes teóricos da corrente realista das relações internacionais, propôs-se a analisar, teoricamente, a resposta de países de segunda ordem à percepção de ameaça representada pela potência dominante durante o governo de George W. Bush. Desses estudos, surgiu a tese do soft balancing, que combinou elementos da teoria da balança de poder de Waltz (1979) com a teoria da balança de ameaças de Walt (2002).

De acordo com os proponentes da referida tese, o balanceamento brando, diferentemente das formas tradicionais de balanceamento, não envolveria tentativas diretas de confrontar ou constranger as preferências do país dominante por meio de alianças militares ou mobilização militar, mas sim de estratégias diplomáticas e institucionais predominantemente não militares, com o propósito de atrasar, frustrar e minar práticas intervencionistas e políticas unilaterais dos EUA, restringindo a projeção política de seu poder militar; resistir à pressão econômica, política e até mesmo militar dos Estados Unidos; aumentar o poder de barganha em negociações 
internacionais, sejam elas relacionadas a questões específicas ou a amplos acordos de governança global; demonstrar aos EUA as limitações de sua influência, isto é, que nem sempre os demais países irão aceitar resignadamente a imposição das preferências da potência hegemônica; e desfrutar maior autonomia em relação aos Estados Unidos (PAPE, 2005; PAUL, 2005; WALT, 2006).

Segundo a tese do soft balancing, o comportamento externo do país dominante e sua percepção por parte das lideranças políticas nos países de segunda ordem são considerados fatores decisivos para o surgimento de estratégias de balanceamento brando. Quer dizer, não basta o unipolo apresentar uma postura revisionista em sua política externa, é necessário também que os demais Estados o percebam como uma ameaça indireta ou potencial (PAUL, 2004; PAPE, 2005; WALT, 2006). Nada obstante, as percepções e motivações dos líderes políticos dos países de segunda grandeza têm recebido pouca atenção teórica e empírica na literatura acadêmica sobre o soft balancing. Com efeito, boa parte dos estudos tem apresentado um forte viés normativo a favor dos condicionantes sistêmicos desse tipo de comportamento estatal, especialmente a distribuição mundial de poder e as atitudes da potência hegemônica. Os Estados de segunda grandeza, via de regra, são tidos como atores unitários, que respondem aos estímulos sistêmicos a partir da sua posição relativa na hierarquia mundial de poder, de modo que as motivações originais dos atores políticos têm sido negligenciadas para a verificação da ocorrência da estratégia de balanceamento brando (ART, 2006; HE; FENG, 2008). Reproduz-se, dessa forma, o argumento lógico da teoria neorrealista de Waltz (1979), segundo o qual o equilíbrio de poder surge como resultado não necessariamente intencional da ação dos Estados, que, levados pela anarquia internacional a priorizar a segurança nacional como seu interesse absoluto, acabam costurando alianças e arregimentando forças que levam a um resultado sistêmico - a balança de poder - nem sempre pretendido.

A negligência das motivações políticas dos Estados que supostamente estão engajados na estratégia de balanceamento brando ensejou fortes críticas, dentro da própria escola realista, à tese de soft balancing. Como argumentam Liber e Alexander (2005), além de difícil operacionalização empírica, o conceito de balanceamento brando muitas vezes é confundido com a mera barganha política ou com fricções diplomáticas corriqueiras da política internacional. No mesmo diapasão, Brooks e Wolhforth (2005) afirmam que a tese do soft balancing se torna infalsificável ao não considerar explicações alternativas para os fenômenos que supostamente constituem evidências de balanceamento brando, tais como: 
interesses econômicos, preocupações de segurança regional, disputas políticas e incentivos políticos domésticos. Desse modo, uma forma de falsificar o conceito seria demonstrar que os Estados que praticam balanceamento brando estariam dispostos a abdicar de outros interesses para contrariar o país dominante. Em defesa da tese do soft balancing, Walt (2009) admite que as motivações dos atores realmente são fundamentais para definir se um comportamento de política externa constitui um exemplo de balanceamento brando ou não, o que acaba exigindo maiores esforços daqueles que se propõem a empregar o conceito em análises empíricas. Para o autor, no entanto, a dificuldade da operacionalização do balanceamento brando não significa ser ele inútil ou infalsificável.

Nada obstante seu uso inicialmente restrito ao exame das políticas externas de países de segunda ordem, não demorou muito para que a tese do soft balancing logo fosse aplicada na análise do comportamento internacional de países emergentes, especialmente China, Índia, Brasil e África do Sul. Hurrel (2009) certamente foi um dos pioneiros nesse empreendimento. Para o autor, em um contexto global de crescente interdependência entre as nações, a relevância e utilidade da teoria da balança de poder não se restringe aos casos nos quais o Estado dominante representa uma ameaça militar à segurança dos demais países. Isso porque 0 problema do poder não balanceado envolve também a possibilidade de os países mais poderosos "ditarem as regras do jogo" aos mais frágeis, distorcerem os termos de cooperação em seu próprio benefício, imporem seus próprios valores e costumes nas relações internacionais e, desse modo, solaparem as normas essenciais para a estabilidade do sistema internacional (HURREL, 2009). Nas palavras de Hurrel, "é por esta razão que a percebida necessidade de conter o poder dos Estados Unidos compõe um elemento muito importante das políticas de Brasil, Rússia, Índia e China em muitas áreas e muitos assuntos aos quais céticos gostariam de consignar à área da 'barganha diplomática normal'“ (2009, p. 36).

Ao definir o que seria uma estratégia de soft balancing, Hurrel (2009), assim como Walt (2009), enfatiza a motivação e o propósito dos Estados de contrabalançar a potência estadunidense, estabelecendo, assim, um critério de verificação. Para ele, apenas as ações externas em resposta à concentração de poder dos EUA, isto é, com motivações de conter a primazia estadunidense, podem, de fato, ser representativas do comportamento de balanceamento brando. Essa especificação coloca uma obrigação de pesquisa ao autor: para provar que as ações dos Estados de fato caracterizaram-se como soft balancing, é preciso aferir a motivação por trás das diferentes iniciativas, em vez de deduzi-las do modelo teórico. Hurrel 
(2009), entretanto, não examina detalhadamente as intenções dos governantes brasileiros na abertura dos contenciosos contra os EUA para chegar à conclusão de que o ativismo do Brasil na OMC é evidência de soft balancing. Outros autores cometem o mesmo equívoco ao replicar o argumento de Hurrel (2009) e não fornecer evidências de que os governantes brasileiros foram motivados por razões de política de poder ao decidirem acionar os Estados Unidos no OSC (FLEMES, 2009, 2010). Nesse caso, em específico, motivações econômicas e não políticas podem ter levado o Brasil a abrir os contenciosos contra os Estados Unidos. Verificar as motivações dos governantes brasileiros, especialmente no âmbito do Órgão de Solução de Controvérsias da OMC, é a tarefa que nos propomos nas seções seguintes.

\section{0 balanceamento dos Estados Unidos como propósito da Política Externa Brasileira}

As primeiras manifestações, no discurso diplomático brasileiro, do objetivo de promover a multipolarização da ordem mundial surgiram ao final do segundo governo de Fernando Henrique Cardoso (1999-2002), sobretudo após o recrudescimento do unilateralismo na política externa dos Estados Unidos na virada do século XX. Duas ações importantes dos EUA catalisaram a reação: a aprovação do fast track no Congresso dos EUA, em junho de 2002, eliminando da mesa de negociações da ALCA e OMC quase 300 produtos prioritários para o Brasil, e o anúncio da “Doutrina Bush", em resposta aos atentados de 11 de setembro de 2001, claramente desrespeitando prerrogativas do Conselho de Segurança na manutenção da paz e ordem internacionais.

À imediata repercussão na mídia mundial, seguiram-se críticas contundentes por parte da diplomacia brasileira, já no governo Fernando Henrique Cardoso, expressas a chefes de Estado de países emergentes que assumidamente se engajavam na construção de um mundo multipolar, como China e Rússia. Em janeiro de 2002, na esteira dos acontecimentos de 11 de setembro do ano anterior, o presidente brasileiro afirmou em visita oficial à Rússia:

os acontecimentos de 11 de setembro tornaram ainda mais necessário o fortalecimento do diálogo político entre o Brasil e a Rússia. Defendemos uma ordem multipolar, que se oriente segundo a igualdade entre os Estados e valorize o papel das Nações Unidas (CARDOSO, 2002, p. 36, grifo nosso). 
A estratégia de multipolarização da ordem global, se foi apenas moderadamente anunciada por Fernando Henrique Cardoso, tornou-se um dos eixos da diplomacia de Luiz Inácio Lula da Silva a partir de janeiro de 2003. Tal propósito certamente pesou na escolha dos dois principais nomes para o Itamaraty durante os governos Lula - ministro Celso Amorim e secretário-geral Samuel Pinheiro Guimarães que há algum tempo expressavam críticas duras à primazia dos EUA na política internacional do pós Guerra Fria, mesmo antes dos acontecimentos de 11 de setembro de 2001 (AMORIM, 1998a, 1998b; GUIMARÃES, 2001a, 2001b). De fato, em entrevista concedida à Gazeta Mercantil em 2002, o embaixador Celso Amorim, já nomeado chanceler do governo Lula, transmitia o desejo brasileiro de contribuir para a construção de uma ordem internacional multipolar:

Na realidade global de hoje, todo mundo acentua o grande predomínio americano, e ele é verdadeiro. Mas há vários outros polos de poder. O Brasil pode contribuir para a multipolaridade, que é saudável para todos e até para a grande potência. Podemos contribuir com o diálogo franco com países europeus, com a China, Rússia, Índia, África. (AMORIM, 2002, p. 327, grifo nosso)

No mesmo diapasão, Samuel Pinheiro Guimarães, em seu discurso de posse como Secretário-Geral do Itamaraty, em 2003, colocou a questão nos seguintes termos:

O mundo multipolar sem hegemonias em que todos os Estados obedeçam ao Direito Internacional e procurem resolver suas controvérsias de forma pacífica é o mundo que mais interessa à nação brasileira. Cada dia, cada ato da Chancelaria, deve procurar contribuir para este objetivo. As organizações multilaterais, em especial as Nações Unidas e a OEA, devem contribuir para esses objetivos, e o Brasil nelas atuará de forma ativa. (GUIMARÃES, 2003, p. 69, grifo nosso)

Certamente, a posição expressa por Amorim e Guimarães fizeram eco à postura histórica do Partido dos Trabalhadores e de Lula, pois atendiam simultaneamente a um propósito da política internacional e a uma aspiração das bases do governo, historicamente críticas dos Estados Unidos (PT, 1994, 1998, 1999). Como relata Amorim, houve uma imediata identificação entre suas ideias e às do líder de governo logo na primeira conversa que manteve com Lula. Da mesma forma, Samuel Pinheiro Guimarães, que havia sido afastado do núcleo decisório da 
diplomacia de Fernando Henrique Cardoso pela postura crítica em relação à participação brasileira nas negociações da ALCA, foi reintegrado ao governo como segundo homem mais importante das Relações Exteriores. Assim, de elemento retórico a multipolarização tornou-se um importante motor da política externa a partir de 2003.

Essa orientação de política externa emergiu com força nas discussões da ONU sobre a intervenção no Iraque, quando ficou evidente que o predomínio da força militar dos EUA lhe permitiria ignorar as resoluções multilaterais. Nesse momento, o Brasil compôs a coalizão intitulada "Frente pela Paz", junto com Alemanha, França e Rússia para opor resistência à invasão do Iraque. Ao buscar uma frente contra a guerra, o governo não defendia apenas o princípio clássico da diplomacia brasileira da solução pacífica de controvérsias, mas buscava agir concretamente para obstruir a ação unilateral dos EUA, essa secundada pela "Coalizão da Vontade", e impedir que os planos de invasão do Iraque se consumassem (AMORIM, 2013). Nas palavras do então chanceler brasileiro,

Todos conhecem bem o fato de que o esgotamento da ordem bipolar da Guerra Fria gerou o que foi chamado por uns de "momento unipolar", e por outros de "ilusão unipolar”. No início do século XXI, e especialmente na esteira dos atentados de 11 de setembro, a unipolaridade conheceu seu auge. Ao contrário do que pretenderam alguns de seus ideólogos, a primazia da superpotência remanescente não gerou estabilidade no sistema. Como a invasão do Iraque em 2003 demonstraria, a extrema concentração de poder [...] era fonte de instabilidade em nível global. Até porque era um incentivo ao uso fácil da força. O estímulo aos elementos incipientes da multipolaridade foi a resposta que o Brasil e outros países procuraram oferecer aos riscos do desequilíbrio unipolar. A oposição clara à guerra do Iraque e a defesa da integridade do sistema multilateral das Nações Unidas [...] não deixou de conter [...] elementos da busca de um melhor equilíbrio do poder mundial. (AMORIM, 2016, p. 219-220, grifo nosso)

Na rodada Doha da OMC, mesmo quando perseguindo interesses comerciais concretos, a diplomacia do governo Lula realçou que um dos objetivos ao liderar a criação do G20 comercial foi justamente "multipolarizar” a estrutura das negociações comerciais multilaterais, tradicionalmente estribada nos dois polos capitaneados pelos EUA e pela União Europeia (UE). Conforme Amorim (2011), até a V Conferência Ministerial de Cancún, a correlação de forças nas negociações comerciais agrícolas da OMC punha em lados opostos os Estados Unidos, apoiados 
pelo grupo de Cairns, na demanda por maior acesso ao mercado agrícola, e a União Europeia que,à frente de países em desenvolvimento com agricultura familiar e de subsistência, a exemplo da Índia, esposava uma posição mais protecionista e obstrucionista. Além de fragmentar a atuação conjunta dos países em desenvolvimento e, assim, impedir o avanço das negociações agrícolas, tal estrutura "bipolar" permitia que, ao final, os EUA e a UE chegassem a um acordo comum que lhes fosse benéfico em detrimento dos países em desenvolvimento. Após Cancún, portanto, a estrutura negociadora da OMC teria se modificado, tornando-se "multipolar", com a introdução do G20 como mais um polo de poder frente aos Estados Unidos e à União Europeia (AMORIM, 2011, 2015).

Com a criação oficial do BRIC em 2009, o governo Lula se juntou a outras potências emergentes na preconização de uma ordem internacional multipolar, supostamente mais equilibrada e justa, a ser alcançada através da promoção de reformas nas principais instituições internacionais (e.g. Fundo Monetário Internacional, Banco Mundial e Conselho de Segurança das Nações Unidas) e de sorte a conter a primazia das grandes potências estabelecidas, garantindo, assim, maior participação dos países em desenvolvimento no processo decisório global (BRIC, 2009, 2010). Nas palavras de Amorim (2008, p. 211), a primeira reunião ministerial do BRIC ocorrida em Ecaterimburgo, que resultaria na criação oficial do grupo um ano depois, "diz mais sobre a multipolaridade do que quaisquer palavras”, porquanto Brasil, Rússia, Índia e China “buscam se fortalecer politicamente como um bloco que ajude a equilibrar e democratizar a ordem internacional deste início de século"

Por fim, projetos regionais de integração e cooperação - particularmente o MERCOSUL e a UNASUL - foram igualmente justificados, em diversos momentos, como necessários para a "multipolarização" da ordem internacional vigente, fazendo da América do Sul mais um polo de poder dentro de um mosaico mundial de contornos cada vez mais multipolares (BRASIL, 2004; SILVA 2009). No que diz respeito ao primeiro projeto de integração, é emblemática a elaboração, em 2007, do Convênio do Sistema de Pagamentos em Moeda Local no âmbito do MERCOSUL, que tornou facultativa aos países membros do bloco a utilização de moedas locais no comércio exterior intrarregional em substituição ao dólar (VADELL; LAMAS; RIBEIRO, 2009). No que toca à UNASUL, o anseio pela multipolaridade e equilíbrio de poder no mundo, a ser logrado por meio do aprofundamento da integração regional, encontra-se explícito logo no preâmbulo do seu tratado constitutivo, segundo o qual: “a integração é um passo decisivo para o fortalecimento do 
multilateralismo e a vigência do direito nas relações internacionais para lograr um mundo multipolar, equilibrado e justo” (UNASUR, 2018, p. 3, tradução nossa ${ }^{3}$ ). Conforme argumentam Cervo e Bueno (2010), a UNASUL, em termos geopolíticos, criou um polo de poder regional que, embora não se caracterizasse como uma aliança militar, permitiu que os contenciosos entre os países sul-americanos fossem resolvidos regionalmente, a partir de suas premissas próprias de segurança e sem a interferência de forças externas. Assim, foi através da UNASUL, e não da OEA ou por mediação estadunidense, que se estabilizaram crises políticas na região como a da Bolívia, em 2008, e entre Colômbia e Venezuela, em 2010. Também por meio da UNASUL, o governo brasileiro condenou enfaticamente a iniciativa colombiana de assinar um acordo de cooperação militar com os EUA em 2010, que previa a instalação de sete bases militares estadunidenses em território colombiano (VIGEVANI; RAMAZINI JÚNIOR, 2014).

Em suma, na medida em que foram justificadas e efetivamente contribuíram, ainda que de maneira branda e limitada, para a maior distribuição de poder no mundo, as iniciativas da política externa brasileira descritas acima evidenciam que, mais do que um simples jargão retórico, o propósito de promover a multipolarização da ordem internacional e, consequentemente, balancear o poder dos Estados Unidos, foi uma das motivações que orientou a diplomacia brasileira sobretudo a partir do governo Lula (2003-2010). Sendo assim, nesses casos, o conceito de soft balancing pode ser útil para interpretar a estratégia de política externa do Brasil, particularmente em relação aos EUA. O problema se coloca com relação a outras iniciativas de política externa, entre as quais não motivadas explicitamente pelo desejo de redistribuir o poder mundial, como acontece com a atuação brasileira no Órgão de Solução de Controvérsias da OMC. Seriam os contenciosos abertos pelo Brasil contra os Estados Unidos no OSC evidências válidas da tese do balanceamento brando? Para que assim o seja, respeitando-se as condições de verificação apontadas pelo próprio intelectual, a atuação brasileira no OSC também deve, no mínimo, ter apresentado como propósito, entre outros, balancear o poder estadunidense ou, no discurso diplomático, promover a “multipolarização do mundo”. Na seção que segue, buscamos verificar se esse propósito realmente se verificou.

\footnotetext{
3 "La integración es un paso decisivo hacia el fortalecimiento del multilateralismo y la vigencia del derecho em las relaciones internacionales para lograr un mundo multipolar, equilibrado y justo”. (UNASUR, 2018, p. 3, versão original)
} 


\section{A participação brasileira no Órgão de Solução de Controvérsias}

Para verificar se a atuação brasileira no OSC foi norteada por considerações de equilíbrio de poder, nesta seção buscamos os seguintes objetivos: (i) analisar o processo decisório de uma das disputas mais importantes movidas pelo Brasil contra os EUA, sobre subsídios concedidos à produção de algodão; e (ii) analisar de forma desagregada e comparativa as disputas iniciadas pelo Brasil no período, para verificar se o número de disputas contra os EUA cresceu depois de 2001, especialmente em comparação com países que, por terem se declarado aliados dos EUA, indiscutivelmente não adotaram a estratégia de soft balancing.

\subsection{Os números}

Não obstante a reorientação da diplomacia brasileira após 2003, seja adotando a "multipolarização" ou a defesa mais vigorosa da "autonomia", as estatísticas sobre a abertura de disputas na OMC nos últimos 25 anos (1995-2015) evidenciam alguns paradoxos. Primeiro, o amplo período 1995-2002 concentra grande parte das consultas levadas pelo governo brasileiro ao OSC, embora com dois padrões distintos: entre 1995-1999, há maior dispersão dos países contestados pelo Brasil; enquanto em 2001-2002, os casos voltam-se, sobretudo, para os EUA (Tabela 1).

Tabela 1: Disputas iniciadas pelo Brasil, por país reclamado (1995-2015)

\begin{tabular}{l|ccc|c|c}
\hline Reclamado & $\mathbf{1 9 9 5 - 2 0 0 0}$ & $\mathbf{2 0 0 1 - 2 0 0 2}$ & $\mathbf{2 0 0 3 - 2 0 0 9}$ & $\mathbf{2 0 1 0 - 2 0 1 5}$ & TOTAL \\
\hline EUA & 3 & 5 & 2 & 0 & 10 \\
União Europeia & 4 & 2 & 0 & 1 & 7 \\
Outros PDs & 2 & 1 & 0 & 0 & 3 \\
América do Sul/México & 3 & 1 & 0 & 0 & 4 \\
Outros PEDs & 1 & 0 & 0 & 2 & 3 \\
\hline TOTAL & $\mathbf{1 3}$ & $\mathbf{9}$ & $\mathbf{2}$ & $\mathbf{3}$ & $\mathbf{2 7}$ \\
\hline Média anual & $\mathbf{2 , 2}$ & $\mathbf{4 , 5}$ & $\mathbf{0 , 3}$ & $\mathbf{0 , 4}$ & $\mathbf{1 , 3}$ \\
\hline
\end{tabular}

Fonte: Organização Mundial do Comércio (www.wto.org). Elaboração do autor, ano.

O ano de 2001 é justamente quando toma corpo o propósito de multipolarização - evidência a favor da tese de soft balancing -, mas é também quando ocorrem outros eventos importantes no campo comercial: (i) tramitava no Congresso dos EUA fast track que retirou produtos agrícolas que o governo brasileiro esperava ver liberalizados via ALCA ou Rodada Doha; (ii) a legislação brasileira de propriedade intelectual era questionada pelos EUA, acirrando os ânimos nas 
questões comerciais; (iii) a Camex estava em reformulação; (iv) estava se criando a coordenação de contenciosos no MRE, com a simultânea capacitação de diplomatas em questões econômicas e (v) ganhava força o grupo desenvolvimentista no governo. Portanto, há indícios para a tese de soft balancing, embora haja tantos outros que apontem ser os contenciosos sobretudo um meio de abrir mercados quando outros espaços se fecham.

Por outro lado, paradoxalmente, o número de disputas contra os Estados Unidos caiu muito depois de 2003, justamente quando Lula assumiu o governo e pôs em marcha iniciativas que o próprio Amorim disse estarem voltadas para "desconcentrar poder mundial". Nos 13 anos de governo do Partido dos Trabalhadores, foram abertas apenas 2 consultas contra os EUA, frente a 8 consultas nos 8 anos de governos do PSDB. Esses dados sugerem que o discurso de multipolarização de Lula, embora possa explicar as coalizões formadas nas negociações multilaterais, como o IBAS, ou a consolidação dos BRICS, não se manifestou na atuação brasileira no Órgão de Solução de Controvérsias. Welber Barral (2015), que foi Secretário do Comércio Exterior do MDIC durante alguns anos, sugere que esse comedimento no período Lula ocorreu porque, entre 2003 e 2008, o governo esperou abrir mercados na Rodada Doha, aguardando seus resultados antes de avançar litigiosamente os temas comerciais, muito embora haja depoimentos que indiquem exatamente o contrário, de que o OSC foi usado de maneira complementar às negociações multilaterais, seja para forçar a inclusão de certos temas na agenda, seja para angariar poder de barganha ${ }^{4}$. Outra hipótese é que a Coordenação de Contenciosos do Itamaraty, criada em outubro de $2001^{5}$,

4 Segundo Cozendey ([s.d.], p. 6), ”assim o sistema de solução de controvérsias passa a ser tanto fonte de iniciativas de negociação, quanto fonte de poder de barganha no contexto das negociações. Passa, ao mesmo tempo, a entrar nos cálculos do negociador a opção de não acordar uma nova regra e confiar que os resultados do sistema de solução de controvérsias lhe serão favoráveis”.

5 O Decreto n. 3.959, de 10 de outubro de 2001, criou a Coordenação de Contenciosos no Ministério de Relações Exteriores, subordinada à Subsecretaria Geral de Assuntos de Integração, Econômicos e de Comércio Exterior. Algumas justificativas à época foram dadas pelo Secretário Geral Seixas Corrêa: “A criação da coordenação-geral para contenciosos deve-se à importância de um acompanhamento específico e com maior grau de especialização nas questões por assim dizer "judiciais” (os chamados "panels”) em que o país se encontra envolvido não só no contexto da OMC, mas também no âmbito dos mecanismos de solução de controvérsias do Mercosul." (Corrêa, 2001, p 342). Celso Lafer, então ministro, também comentou o assunto em entrevista ao Correio Brasiliense em 29 de janeiro de 2001 ("Mobilização para Negociar a ALCA"): “uma ideia que tenho em relação ao Itamaraty é criar um departamento de contenciosos econômicos que concentre a competência no âmbito do Itamaraty e possa fazer essa ponte com acadêmicos e empresários(referência?)(...) tomei a decisão de destinar todos os diplomatas da última turma do Instituto Rio Branco para as divisões econômicas, com vistas a assegurar pessoal suficiente para enfrentar a considerável carga de trabalho que implicam as diversas negociações em que estamos envolvidos" (referência?). 
em vez de facilitar a abertura de processos, na verdade conteve as demandas injustificadas do setor privado, fazendo uma "triagem legal" antes de iniciar contenciosos. Como visto no estudo de caso, esse propósito esteve nítido nas articulações políticas que levaram ao contencioso do algodão. De qualquer forma, não parece ter sustentação a ideia de que o governo usou a política comercial como forma de contra-hegemonia, pelo menos não nas disputas da OMC, pois sua estratégia de enfrentamento dos EUA não foi acompanhada de mais casos.

Outra maneira de tentar capturar o viés político das disputas comerciais é analisar o número de casos abertos por um país para cada dólar exportado. Partimos da suposição de que, quanto mais intenso o fluxo comercial, mais recorrente deverão ser as restrições comerciais enfrentadas e, portanto, as disputas no OSC. Restringimos a análise a alguns reclamantes: Brasil e Índia, por supostamente serem praticantes do soft balancing; Canadá e Japão, pela tradicional aliança com os EUA; e os países da União Europeia. Além disso, são esses os únicos países que acionaram o Órgão de Solução de Controvérsias mais de 20 vezes entre 1995 e 2015.

Sob esse prisma, alguns aspectos chamam atenção. Primeiro, Brasil e Índia são muito ativos no OSC em geral (Tabela 2, linha "Mundo"), e não apenas contra os EUA: nenhum dos países analisados abriu tantas disputas na OMC por valor de dólar exportado quanto esses emergentes. Se restringimos a análise às disputas iniciadas contra os EUA, o valor é ainda mais elevado. Isso poderia indicar um "viés político" de Brasil e Índia, já que alvejam a potência com maior frequência do que fazem com outros. Mas, como as disputas iniciadas pelo Japão e pela União Europeia contra os EUA têm as mesmas características, pode-se inferir que o elevado índice expressa mais o protecionismo americano do que a orientação política do resto do mundo. Essa afirmação, aliás, se estende ao Brasil: ele frequenta o banco dos réus no OSC mais recorrentemente do que se poderia esperar pelo valor de suas importações (Tabela 2). 
Tabela 2: Índice de disputas*, por reclamante e reclamado

\begin{tabular}{lccccc}
\hline \multirow{2}{*}{ Reclamado } & \multicolumn{5}{c}{ Reclamante } \\
\cline { 2 - 6 } & Brasil & Índia & Canadá & Japão & União Europeia \\
\hline EUA & 2,7 & 2,2 & 0,28 & 0,35 & 0,59 \\
União Europeia (28) & 1,2 & 1,5 & 0,22 & 0 &. \\
Outros PDs & 1,9 & 0 & 0,82 & 0,36 & 0,22 \\
Brasil & $\cdot$ & 2,5 & 3,6 & 2,8 & 0,93 \\
Índia & 0 & & 4,1 & 0 & 1,8 \\
China & 0 & 0 & 1,9 & 0,13 & 0,41 \\
Outros PEDs e Rússia & 1,7 & 0,31 & 0,72 & 0,13 & 0,33 \\
\hline Mundo & $\mathbf{1 , 1}$ & $\mathbf{0 , 8}$ & $\mathbf{0 , 5 1}$ & $\mathbf{0 , 1 8}$ & $\mathbf{0 , 1 2}$ \\
\hline
\end{tabular}

* [Disputas iniciadas (1995-2015) / Valor exportado(1995-2014) ${ }^{*} 10^{8}$

Fonte: Cálculo dos autores, com dados da UNCTAD (comércio) e OMC (disputas).

Por fim, as disputas iniciadas pelo Brasil e Índia, em comparação com as de Canadá, Japão e União Europeia, sugerem haver certo viés Norte-Sul nas disputas: Brasil e Índia têm índices mais elevados em disputas contra UE, EUA e outros países desenvolvidos; enquanto os valores dos casos abertos por Canadá, Japão e União Europeia são maiores contra Índia, China, Brasil e outros países em desenvolvimento. Parece, pois, que países desenvolvidos abrem mais casos contra países em desenvolvimento, em relação ao valor exportado, do que contra países desenvolvidos, e vice-versa. Essa observação deve ser lida com cautela: serve mais como evidência de que a tese de soft balancing não explica bem o padrão de ação dos países no OSC do que como prova definitiva de que há um viés Norte-Sul nesse órgão - hipótese que exigiria mais provas para sustentar-se.

\subsection{Um caso típico: algodão}

Uma forma de averiguar se o Itamaraty utilizou o Órgão de Solução de Controvérsias para redistribuir o poder mundial é analisar o processo decisório que levou à abertura de disputas contra os EUA. Assim é possível identificar quem propôs a saída litigiosa, qual a posição adotada pelo Itamaraty e quais setores do governo se posicionaram a favor ou contra.

A prova é mais contundente se analisamos casos iniciados após 2003, período em que o governo brasileiro intensificou as críticas à postura unilateral dos Estados Unidos. Se o propósito de multipolarização desempenhou algum papel na diplomacia brasileira, terá certamente sido após esse ano. Dentre eles, o mais significativo foi a disputa do algodão, com pedido de consultas apresentado à 
OMC em setembro de 2002 e de painel em março de 2003, pois questionou um dos pilares da política agrícola estadunidense, a Farm Bill, ainda durante a vigência da Cláusula da Paz. O resultado, favorável ao Brasil, dá ideia da importância do caso: pela primeira vez a OMC autorizou, como retaliação, contramedidas em matéria de propriedade intelectual para uma disputa sobre bens, em montante até então nunca alcançado, US\$ 147 milhões anuais (AZEVÊDO, 2013).

A disputa foi o ápice de anos de queixa, por parte do governo brasileiro, com relação aos resultados da Rodada Uruguai do GATT (1986-1994). O Acordo Agrícola incorporado à legislação da OMC ao final da Rodada, resultado de barganha entre Estados Unidos e Comunidades Europeias no conhecido Blair House Agreement, de 1992, nunca satisfez plenamente a diplomacia comercial brasileira. Desde o encerramento das negociações, diplomatas aproveitaram cada oportunidade pública para criticar o resiliente protecionismo agrícola nos países desenvolvidos, mantendo viva a pauta de liberalização para o setor até que, em novembro de 2001, após frustradas tentativas anteriores, na Reunião Ministerial da OMC, teve início uma nova rodada de negociações com mandato abrangente sobre o tema: redução, com vistas à eliminação, de subsídios às exportações e reduções substantivas em subsídios internos com efeito distorcivo ${ }^{67}$.

Meses antes da reunião de Doha, no início de 2001, círculos do governo brasileiro já buscavam formas mais céleres e eficazes de atacar os subsídios agrícolas europeus e estadunidenses por meio do Órgão de Solução de Controvérsias. O núcleo dessa articulação não partiu do Itamaraty, mas do Ministério da Agricultura, Pecuária e Abastecimento, particularmente depois que assumiu a Secretaria de Produção e Comercialização o ex-presidente da Sociedade Rural Brasileira Pedro Camargo Neto, durante a gestão do ministro Marcus Vinicius Pratini de Moraes (1999-2003). Partiu dessa secretaria a iniciativa de avaliar a legalidade dos subsídios agrícolas à luz do Acordo Agrícola da OMC ${ }^{8}$ O Artigo 13

6 No excerto sobre agricultura, previa-se: "nos comprometemos com negociações abrangentes destinadas a: melhorias substanciais no acesso a mercados; reduções, com vista à eliminação gradual, de todas as formas de subsídios à exportação; e reduções substanciais no apoio interno que distorce o comércio” (OMC, 2001,, tradução nossa). A crítica brasileira ao protecionismo agrícola nos países centrais pode ser vista nas diversas intervenções públicas realizadas no período, compiladas na coletânea Resenhas de Política Externa.

7 Versão original do texto citado na nota anterior: "we commit ourselves to comprehensive negotiations aimed at: substantial improvements in market access; reductions of, with a view to phasing out, all forms of export subsidies; and substantial reductions in trade-distorting domestic support."

8 É o próprio Pedro Camargo Neto (2014) quem afirma, em depoimento anos após o contencioso, ter tido a iniciativa de recorrer à OMC para combater os subsídios estadunidenses: "no início de 2001 iniciamos internamente no Ministério da Agricultura, Pecuária e Abastecimento - MAPA - um estudo sobre os subsídios estadunidenses 
desse acordo instava as partes a exercerem "duerestraint" - comedimento - nos recursos ao OSC durante o período de implementação (final de 2003), desde que subsídios domésticos não excedessem os níveis de 1992. Em estudo sobre a soja nos EUA, o Ministério da Agricultura brasileiro constatou contribuições financeiras muito superiores aos níveis de 1992. Estavam dadas assim as justificativas para recorrer aos tribunais, mesmo enquanto vigente a Cláusula da Paz. E como a situação repetia-se em outras culturas, o Ministério da Agricultura, em discussões com produtores e demais membros do governo, definiu preliminarmente três setores que poderiam sustentar disputas: soja e algodão, contra os EUA, e açúcar, contra a União Europeia.

Enquanto o Ministério da Agricultura buscava apoio para iniciar a disputa, já que a palavra final partiria de uma decisão do Conselho de Ministros da Camex ${ }^{9}$, o Itamaraty tentava freá-la. Essa era a percepção tanto de Camargo Neto, referido Secretário de Produção e Comercialização do MAPA fortemente engajado no processo ${ }^{10}$, quanto do ex-Secretário Executivo da Camex Roberto Giannetti da Fonseca11, homem com fortes vínculos com a indústria exportadora paulista e envolvido no processo de "reestruturação industrial” encampado por Fernando Henrique Cardoso para recuperar as reservas cambiais a partir de 1999. Camargo Neto sentiu as resistências do Itamaraty aumentarem ao longo de 2001, quando “alterações nos cargos de chefia do MRE começaram a dificultar o processo de

para a soja. O maior produto agrícola em renda do Brasil vinha apresentando permanente crescimento em área plantada e produtividade. Tornávamo-nos o líder de hoje. Simultaneamente, coincidência ou não, os estadunidenses aumentavam os subsídios fornecidos a seus sojicultores [...] É importante lembrar que os contenciosos se iniciaram dentro do MAPA e não provocados pelos setores prejudicados como é o usual” (referência?) Camargo Neto (2014, p 32).O importante papel de Camargo Neto tem respaldo também em comentário do advogado responsável pelo caso, Scott D. Andersen, que, em citação de Oliveira (2007, p. 23), teria o classificado como “o chefão, o visionário dos casos relativos ao algodão e ao açúcar” (referência?) (Oliveira 2007, p. 23).

9 A Camex foi criada pelo Decreto n. 1.386, de 6 de fevereiro de 1995. Quando da criação, sua composição era: ministro-chefe da Casa Civil; das Relações Exteriores; da Fazenda, do Planejamento e Orçamento; da Indústria, do Comércio e do Turismo; da Agricultura, Abastecimento e Reforma Agrária. Houve alterações posteriores (FERNANDES, 2010, 2013).

10 Em depoimento citado por Oliveira (2007, p. 23), Camargo Neto afirmou: “Alguns funcionários do Ministério das Relações Exteriores não desejavam enfrentar a superpotência mundial no terreno das questões agrícolas. Eu levei até eles um estudo sobre a contestação dos subsídios e eles disseram, 'Traga-me outro'. A seguir, eu levei dois e eles me pediram outros quatro".

11 Em entrevista a Ivan Fernandes (2010, p. 97), o ex-Secretário Executivo da Camex entre 2000 e 2002 afirmou que o MRE, cujo ministro era Celso Lafer, e o próprio MDIC, dirigido pelo também diplomata Sérgio Amaral, eram contra a abertura de painel contra os EUA devido à falta de pessoal qualificado para conduzir o tema e por receio de enfrentar um adversário tão preparado. Ainda segundo Giannetti, a decisão para iniciar o contencioso foi tomada na própria Camex, por pressões dele próprio, e do ministro da Agricultura Marcus Vinicius Pratini de Moraes. 
aprovação do contencioso" (CAMARGO NETO, 2014, p ?30). O ex-funcionário do MAPA não explica quais foram tais alterações de cargo, mas provavelmente referia-se ele à criação da Coordenação-Geral de Contenciosos Comerciais no MRE em outubro de 2001, para onde foi alocado o diplomata e atual diretor geral da OMC Roberto Carvalho de Azevêdo, já que não houve outras mudanças nos cargos econômicos do Itamaraty naquele ano. Segundo depoimento de Gianneti, também o ministro da Indústria e diplomata de carreira Sérgio Amaral fazia eco às justificativas do Itamaraty: havia grande risco de perder o contencioso; era grande a chance de "ganhar mas não levar"; seria politicamente delicado acionar a OMC durante a vigência da Cláusula da Paz; era prudente aguardar os primeiros sinais da Rodada Doha, que continha um mandato amplo para agricultura; não havia servidores qualificados para lidar com a disputa.

A relutância do Itamaraty se manteve ao longo de 2002, embora a aprovação definitiva da Trade Promotion Authority e da Farm Bill nos EUA, completamente contrárias ao mandato de Doha, tenham contribuído para convencer membros do governo brasileiro que o litígio era a única saída para debelar os subsídios agrícolas. Tais decisões do governo estadunidense foram amplamente cobertas pela mídia brasileira. Notícias da Folha de S. Paulo de maio de 2002 fizeram menção a estudo crítico publicado pela embaixada do Brasil em Washington e a nota divulgada pelo MRE, na qual supostamente informavam que "O Itamaraty poderá acionar a OMC para tentar eliminar subsídios que distorcem a competitividade internacional no setor agrícola” (DIANNI, 2002, p ?). Contraditoriamente, a ofensiva verbal não correspondia à posição oficial do ministério. Um mês após veiculação da notícia na Folha de S. Paulo, na XVI Reunião da Camex, em 6 de junho, o Itamaraty apresentou e teve aprovado parecer contrário ao pedido de consultas na OMC, obstruindo a ofensiva pretendida pelo Ministério da Agricultura.

A resistência só foi vencida em setembro de 2002, quando a Camex aprovou o pedido de consultas à OMC sobre os subsídios ao algodão nos EUA. Segundo Camargo Neto, pesou na votação a posição do ministro da Fazenda Pedro Malan (1995-2002), homem forte dentro do governo que apoiou as consultas, além do ministro da Agricultura Pratini de Moraes, de onde havia partido a demanda pelo contencioso. A essa altura, o pleito já contava com o respaldo das principais associações de classe produtoras de algodão no país, e também de ONGs preocupadas com o impacto dos subsídios sobre pequenos produtores de algodão em países pobres. 
Iniciadas as consultas, coube ao Itamaraty formular parecer à Camex detalhando o programa estadunidense e sugerindo providências. O resultado foi apresentado na XXII Reunião da Camex, em 6 de fevereiro de 2003, quando o representante do MRE sugeriu que fosse feita "pronta solicitação do estabelecimento do painel, se possível na próxima reunião do Órgão de Solução de Controvérsias da OMC, que será realizada no dia 18 de fevereiro de 2003"(CAMEX, 2017).

A enfática defesa da abertura do painel pelo Itamaraty na Camex, embora na contramão da posição até então defendida pelo mesmo ministério, não surpreende. Àquela altura, era outra a composição das forças políticas no governo. Com a posse de Lula em janeiro de 2003, fortaleceram-se as políticas ativas de desenvolvimento econômico, assim como ganharam espaço no Itamaraty as teses mais "autonomistas" em política externa, herdeiras de uma tradição diplomática cultivada desde os anos de 1960, muito presente para os ministros Celso Amorim e o secretário-geral Samuel Pinheiro Guimarães, e também fortemente respaldada por círculos do Partido dos Trabalhadores incorporados ao governo, como Marco Aurélio Garcia, que se tornou assessor especial da Presidência da República para Assuntos Internacionais. Assim como essa recomposição de forças políticas no Estado implicou negociações mais firmes na ALCA e na OMC, também levou ao questionamento de práticas ilegais de comércio via Órgão de Solução de Controvérsias.

Deve-se frisar, contudo, que o contencioso não foi aberto por iniciativa do Itamaraty, mas de uma pasta mais diretamente envolvida com os produtores rurais - o Ministério da Agricultura - que, àquela altura, era comandado por Roberto Rodrigues, figura política de peso junto ao agronegócio, que emprestava apoio ao governo. A posição inicial do Itamaraty, contrária à demanda, paulatinamente perdeu apelo ao longo de 2002, com a ampla divulgação midiática do protecionismo estadunidense manifesto na Farm Bill e na Trade Promotion Authority, e alterou-se completamente com a ascensão do novo governo brasileiro em janeiro de 2003.

\section{Considerações finais}

Em períodos recentes, na medida em que os EUA mostraram que, além de fortes, não se conformariam às regras internacionais - seja no campo da segurança, seja no comércio - progressivamente o governo brasileiro, escudado por um processo de crescimento econômico intensivo que nutria expectativas de grandeza, 
articulou diversas iniciativas que explicitamente buscavam construir um mundo multipolar. Obviamente, como em qualquer articulação política, motivações de poder mesclaram-se com interesses os mais diversos para consolidar uma base de apoio que sustentasse tais iniciativas. Não nos dedicamos a um estudo mais pormenorizado dessas motivações, salvo no caso do algodão aberto pelo Brasil no Órgão de Solução de Controvérsias, onde constatamos a confluência de interesses diversos que compunham o governo Lula.

Em síntese, houve um grande número de disputas iniciadas pelo Brasil contra os Estados Unidos, particularmente no ano de 2001, quando o propósito de "multipolarização do mundo" foi introduzido na agenda da política externa brasileira. Entretanto, quando desagregamos as disputas por ano, os números mostram que a eleição de Lula foi acompanhada pela redução das disputas contra os EUA - lido por certos analistas como uma opção por aguardar as negociações em Doha - o que nos desautoriza a imputar a ação no OSC exclusivamente ao acirramento da diretriz multipolar brasileira, que de fato ocorreu no período. Em segundo lugar, o Itamaraty não tinha competência exclusiva de iniciar os contenciosos, que era dividida com ministérios, como a Indústria e a Agricultura, eivados que estavam pelos interesses que representavam. Pelo forte vínculo mantido com o setor privado, foi deles a iniciativa de questionar juridicamente os subsídios estadunidenses, e não do MRE. O Itamaraty, ao contrário, inicialmente tentou contê-la. A proposta ganhou força por uma reorientação político-ideológica do governo, iniciada em 1999 e com auge em 2003, quando a restauração das contas externas tomou o centro da política econômica e ganharam espaço grupos "desenvolvimentistas" no interior do governo, bastante próximos de uma tradição mais autônoma de política externa que também ascendeu no Ministério. Em meio a tais mudanças, e com a aprovação do fast track em junho de 2002, ficou cada vez mais claro que pouco se conseguiria com as negociações, e que alternativas litigiosas deveriam ser buscadas.

Diante da miríade de interesses confluentes que resultaram na abertura do contencioso, deve-se refletir: qual a utilidade de resgatar o conceito soft balancing para interpretá-lo? Para subsidiar essa reflexão, convém retomar a pergunta inicial: o contencioso foi aberto pelo governo brasileiro com o propósito de oferecer resistência às políticas estadunidenses? Por um lado, sim. A tradição autonomista de política externa respaldada por Lula continha elementos de anti-imperialismo, caros à esquerda, e também a nacionalismos de diferentes estirpes, que muito bem podem ter mobilizado a Camex, já em 2003, para fazer resistência à expansão 
da hegemonia estadunidense. No entanto, notando que o governo brasileiro abriu um painel no OSC contra os EUA, nos deparamos com a necessidade de interpretar uma ação política, imputando-lhe um sentido, na clássica noção de sentido weberiano. E, para tanto, é necessário refletir acerca de certas premissas: quão desejável é, analiticamente, pressupor que a política externa expressa um "motivo" ou "intenção" do governo, e não resulta de diferentes motivos, pretensões e intenções em disputa no Estado?

A nosso ver, considerar, na interpretação, as forças políticas internas ao Estado, em vez de deduzir o comportamento de modelos teóricos que pressupõem um Estado unitário, faz diferença. Não tivesse o governo Lula aberto espaço à tradição autonomista da diplomacia externa brasileira, preservada em círculos importantes do Itamaraty, e não tivesse ele formado uma coalizão desenvolvimentista que incluía defensores aguerridos da liberalização agrícola, a composição da Camex teria sido outra. Falar em soft balancing, nessas circunstâncias, é limitar demasiadamente a explicação para o contencioso comercial em busca de "parcimônia".

\section{Referências}

AMORIM, Celso. A Reforma da ONU. In: IEA - Instituto de Estudos Avançados da Universidade de São Paulo, Conferência proferida no IEA, em 2 de abril de 1998a. Disponível em: http://200.144.254.127:8080/textos/amorimonu.pdf. Acesso em: 20/12/2018.

. Entre o Desequilíbrio Unipolar e a Multipolaridade: o Conselho de Segurança da ONU no Período Pós-Guerra Fria. In: IEA - Instituto de Estudos Avançadas da Universidade de São Paulo. Texto do evento realizado no IEA "O Brasil e as Novas Dimensões da Segurança Internacional”, no dia 11 de setembro de 1998b. Disponível em: http://www.iea.usp.br/publicacoes/textos/amorimdesequil_briounipolar.pdf. Acesso em: 20/12/2018.

AMORIM. Celso. Entrevista do Embaixador Celso Amorim à Gazeta Mercantil, em 18 de dezembro de 2002. In: Resenha de Política Exterior do Brasil, n. 91, ano 29, $2^{\circ}$ semestre de 2002, p. 325-327.

. Artigo do Ministro das Relações Exteriores, Embaixador Celso Amorim, intitulado "Os BRICs e a Reorganização do Mundo", publicado no jornal Folha de São Paulo. Brasília-DF, 08/06/2008. In: Resenha de Política Exterior do Brasil, n. 102, ano 35, $1^{\circ}$ semestre de 2008, p. 211-212.

. Conversas com Jovens Diplomatas. São Paulo: Benvirá, 2011, 600p. 
- Breves Narrativas Diplomáticas. São Paulo: Benvirá, 2013, 168p.

Teerã, Ramalá e Doha: memórias da política externa ativa e altiva. São Paulo: Benvirá, 2015, 520p.

- A grande estratégia do Brasil: discursos, artigos e entrevistas da gestão no Ministério da Defesa (2011-2014). (Ed.) AMORIM, C.; ROCHA, A. J. R. da [et al]. Brasília: FUNAG; São Paulo: Unesp, 2016.

ART, R. J. Correspondence: Striking the Balance. In: International Security, v. 30, n. 3, 2006. AZEVÊDO, R. C. Prefácio. In: (Ed.) BENJAMIN, D. A. O Sistema de Solução de Controvérsias da OMC: Uma perspectiva brasileira. Brasília: FUNAG, 2013, pp. 23-31.

BARRAL, Webber. OMC e os contenciosos. 2015. Disponível em http://jota.uol.com.br/ coluna-barral-omc-e-os-contenciosos-brasileiros. Acesso em 09 de junho de 2018.

BRASIL. Mensagem ao Congresso Nacional: abertura da $2^{\text {a }}$ Sessão Legislativa Ordinária da 52 ${ }^{\text {a }}$ Legislatura/Luiz Inácio Lula da Silva. Brasília: Presidência da República, Secretaria de Comunicação de Governo e Gestão Estratégica, 2004, 260p.

BRIC. Declaração Conjunta dos Líderes dos Países do BRIC. I Cúpula do BRIC; Ecatarimburgo, 16 de junho de 2009. Disponível em: http://brics.itamaraty.gov.br/categoryenglish/21-documents/114-first-summit-2. Acesso em 09 de setembro de 2018.

. II Cúpula: Declaração. Brasília, 15 de abril de 2010. Disponível em: http://brics. itamaraty.gov.br/pt-br/categoria-portugues/20-documentos/74-segunda \% E2 \% $80 \%$ 93declaracao\%20-conjunta. Acesso em 09 de setembro de 2018.

BROOKS, S. G.; WOHLFORTH, W. C. Hard times for soft balancing. In: International Security, v. 30, n. 1, 2005, pp. 72-108.

CAMARGO NETO, Pedro de. O caso do algodão. In: Revista Política Externa; São Paulo: HMG Editora, v. 23, n. 2, 2014, pp. 25-33.

CAMEX. Ata da XXII Reunião da Câmara de Comércio Exterior, de 6 de fevereiro de 2003. Obtida em solicitação feita através do Portal de Acesso à Informação do Governo Federal (http://www.acessoainformacao.gov.br/. acesso em 20 de junho de 2017). CARDOSO, Fernando Henrique. Discurso do Senhor Presidente da República, Fernando Henrique Cardoso, por Ocasião da Cerimônia de Assinatura de Atos. Moscou, 14 de Janeiro de 2002. In: Resenha de Política Exterior do Brasil, ano 29, n. 90, $1^{\circ}$ semestre de 2002, pp. 35-36.

CERVO, A. L.; BUENO, Clodoaldo. História da Política Exterior do Brasil. Brasília: Editora Universidade de Brasília, 2010.

CORREAA, L. F. DE S. A agenda econômico-comercial e reformas no Itamaraty. In: Resenhas de Política Exterior do Brasil, n. 88, $1^{\circ}$ Semestre 2001;

COZENDEY, C. M. B. O sistema de solução de controvérsias da OMC: para além dos contenciosos, a política externa. [s.d.].

DESTRADI, Sandra. Regional powers and their strategies: empire, hegemony, and leadership. In: Review of International Studies, v. 36, 2010, pp. 903-930. 
DIANNI, Cláudia. Brasil vai à OMC contra subsídio que tira competitividade agrícola. In: Folha de São Paulo, 4 de maio de 2002.

FERNANDES, I. F. DE A. L. Burocracia e política: a construção institucional da política comercial brasileira pós-abertura econômica. São Paulo: Universidade de São Paulo. Faculdade de Filosofia, Letras e Ciências Humanas, 2010.

- A construção institucional da política comercial brasileira: a Câmara de Comércio Exterior (CAMEX) no governo Cardoso. In: Revista de Sociologia e Política, v. 21, n. 45, p. 123-148, mar. 2013.

FLEMES, Daniel. India-Brazil-South Africa (IBSA) in the new global order: interests, strategies and values of the emerging coalition. In: International Studies, v. 46, n. 4, 2009.

O Brasil na iniciativa BRIC: soft balancing numa ordem global em mudança? In: Revista Brasileira de Política Internacional; Brasília, v. 53, n. 1, 2010, pp. 141-156.

Network Powers: strategies of change in the multipolar system. In: Third World Quarterly, v. 34, n. 6, 2013.

FONSECA JR, Gelson. BRICS: notas e questões. In: (Org.) PIMENTEL, José Vicente de Sá. O Brasil, os BRICS e a Agenda Internacional. Brasília, FUNAG, 2012, pp. 13-31;

GUIMARÃES, Samuel Pinheiro. Quinhentos Anos de Periferia: uma contribuição ao estudo da política internacional. $3^{\text {a }}$ ed. Porto Alegre: UFRGS; Rio de Janeiro: Contraponto, 2001a. GUIMARÃES, Samuel Pinheiro. Inserção Internacional do Brasil. In: Economia e Sociedade. Campinas; v. 17, 2001b, pp. 1-31.

. Discurso do Embaixador Samuel Pinheiro Guimarães por ocasião da Transmissão do Cargo de Secretário-Geral das Relações Exteriores, em Brasília. In: (Orgs.) SILVA, L. I. L. da.; AMORIM, Celso; GUIMARÃES, S. P. A Política Externa do Brasil. Brasília; IPRI/FUNAG, 2003.

HE, Kai; FENG, Huiyun. If Not Soft Balancing, Then What? Reconsidering Soft Balancing and U.S. Policy Toward China. In: Security Studies, v. 17, n. 2, 2008.

HURREL, Andrew. Hegemonia, liberalismo e ordem global: qual é o espaço para potências emergentes? In: (Org.) HURREL (et. al.) Os BRICs e a ordem global, Introdução. Rio de Janeiro: Editora FGV, 2009.

LIBER, K. A.; ALEXANDER, Gerard. Waiting for Balancing Why the World Is Not Pushing Back. In: International Security, v. 30, n. 1, 2005.

LOPES, D. B. Política Externa na Nova República: os primeiros 30 anos. Belo Horizonte: Editora UFMG, 2017.

OLIVEIRA, M. F. DE. Multilateralismo, Democracia e Política Externa no Brasil: Contenciosos das Patentes e do Algodão na Organização Mundial do Comércio (OMC). In: Contexto Internacional, v. 29, n. 1, 2007, pp. 7-38.

OMC, Doha Ministerial Declaration [WT/MIN(01)/DEC 1], 20 de novembro de 2001.

PAPE, R. A. Soft balancing against the United States. In: International Security, v. 30, n. 1, 2005, pp. 7-45. 
PAUL, T. V. Introduction: The Enduring Axioms of Balance of Power Theory and Their Contemporary Relevance. In: (Orgs.) PAUL, T. V.; WIRTZ, J. J.; FORTMANN, Michel. Balance of Power Theory and practice in the 21st century. Stanford, California Stanford University Press, 2004.

PAUL, T. V. Soft balancing in the age of U.S. primacy In: International Security, v. 30, n. 1, 2005, pp. 46-71.

PT. Lula, presidente: uma Revolução Democrática no Brasil.Bases do Programa de Governo, 1994. . União do Povo - Muda Brasil. Diretrizes do Programa de Governo, 1998. - Resoluções do II Congresso Nacional do Partido dos Trabalhadores. O Programa da Revolução Democrática para a construção de um Brasil livre, justo e solidário. Belo Horizonte (MG), 24 a 28 de novembro de 1999, 54p..

SCHEWELLER, R. L.; PU, Xiaoyu. After Unipolarity: China's Visions of International Order in na Era of U.S. Decline. In: International Security, v. 36, n. 1, Summer 2011, pp. 41-72. STEPHEN, M. D. Rising Regional Powers and International Institutions: The Foreign Policy Orientations of India, Brazil and South Africa. In: Global Society, v. 26, n. 3, 2012. VADELL, J. A.; LAMAS, Bárbara; RIBEIRO, D. M. de F. Integração e Desenvolvimento no MERCOSUL: Divergências e Convergências nas Políticas Econômicas nos Governos Lula e Kirchner. In: Revista Sociologia Política; Curitiba, v. 17, n. 33, 2009, pp. 39-54. VIGEVANI, Tullo; RAMANZINI JÚNIOR, Haroldo. Autonomia, Integração Regional e Política Externa Brasileira: Mercosul e Unasul. In: DADOS - Revista de Ciências Sociais; Rio de Janeiro, v. 57, n. 2, 2014, pp. 517-552.

SILVA, Luiz Inácio Lula da. Discurso do Presidente da República, Luiz Inácio Lula da Silva, na Segunda Sessão Plenária da $5^{\text {a }}$ Cúpula das Américas, em Portof Spain, Trinidad e Tobago, 18 de abril de 2009. In: Resenha de Política Exterior do Brasil, a. 29 , n. $104,1^{\circ}$ semestre de 2009 , pp. 93-98.

UNASUR. Tratado Constitutivo de la Unión de Naciones Suramericanas.Disponível em: http:// www.Unasursg.org/images/descargas/DOCUMENTOS \% 20CONSTITUTIVOS \% 20 DE\%20UNASUR/Tratado-UNASUR-solo.pdf. Acesso: 09 de setembro de 2018.

WALT, S. M. Keeping the World "Off-Balance”: Self-Restraint and U.S. Foreign Policy. In: America Unrivaled: The Future of the Balance of Power. Ithaca, cap. 4, New York.: Cornell University Press, 2002.

. Taming American Power: the global response to US primacy. Harvard University; W. W. Norton \& Company, 2006. . Alliances in a Unipolar World. In: World Politics, v. 61, n. 1, 2009.

WALTZ, K. N. Theory of International Politics. 1 ed. [S.l.]: McGraw-Hill Humanities/ Social Sciences/Languages, 1979. 